\title{
FRENCH AS A THIRD LANGUAGE IN NORWAY: THE INFLUENCE OF THE PRIOR LANGUAGES IN THE ACQUISITION OF WORD ORDER
}

\author{
KJERSTI FALDET LISTHAUG, GURO BUSTERUD \\ AND ANNE DAHL \\ Norwegian University of Science and Technology \\ University of Oslo
}

\section{ABSTRACT}

The present study investigated the acquisition of verb movement in L3 French by L1 speakers of Norwegian with English as their L2. To investigate the impact of previously learned languages in L3 acquisition, we looked at two sentence types with lexical verbs where Norwegian, English, and French differ in systematic ways: a) non-subject initial declarative main clauses and b) subject-initial declarative main clauses with a short sentence-medial adverbial. Students completed acceptability judgment tasks in both the L2 and the L3. Results did not indicate a privileged status for either language as a source of transfer. Rather, there were indications that both prior languages may influence L3 French. We argue that the partially overlapping surface word order with French in each prior language may cause non-target transfer into the L3. Furthermore, higher L2 proficiency was associated with less evidence of L2 transfer in the L3.

Key words: Third language acquisition, word order, V2, second language, transfer

\section{[1] Introduction}

French has a long history as a foreign language in Norwegian schools. Its position and importance in the Norwegian context have varied over the years, and presently, it is one of the foreign languages students can choose either from year 8 (lower secondary education) or from year 11 (upper secondary education) in school. Students who start learning French in Norway today do so in an increasingly multilingual context. In particular, English is taught from year 1 in school and is ubiquitous in most young Norwegians' lives. Students are thus equipped with knowledge of more than one language and have relatively high English proficiency when they start learning French, and teachers of French often report errors which they attribute to the learners' knowledge of English. 
A growing field within research on language acquisition concentrates on the acquisition of a third language (L3) after the native language (L1) and a second language (L2), focusing on how these previously learned languages affect the acquisition of the L3. The present study focuses on L3 learners of French who are L1 speakers of Norwegian but with substantial knowledge of English as an L2, looking at two sentence types where Norwegian, English, and French all differ in systematic ways. Our research questions focus on the impact of previously learned languages on the acquisition of French.

\section{[2] BACKGROUND}

\section{[2.1] Verb placement in French, English, and Norwegian}

We focus on two types of declarative main clauses with lexical verbs: 1) main clauses with a topicalized adverbial, and 2) subject-initial main clauses with sentence adverbials of the type often and always. In the following, we discuss verb movement and describe placement of the verb as the second or third constituent in the sentence types in 1) and 2) in French, English and Norwegian, respectively.

French, English and Norwegian are all SVO languages. The differences in verb placement between these languages are usually treated as evidence of systematically different settings for verb movement (cf. Pollock, 1989; Yang, 2002). Languages differ both in terms of which types of verbs move and how far they move. In French main clauses, all finite verbs undergo leftward movement from $\mathrm{V}$ to I/T. Like French, Norwegian displays leftward verb movement for all finite verbs in declarative main clauses. However, Norwegian verbs obligatorily move higher, to the C position (Åfarli \& Eide, 2003), and Norwegian is thus referred to as a V2 language (cf. Holmberg \& Platzack, 1995; Roberts, 2001). In English, lexical verbs always remain in situ. Auxiliaries move to $\mathrm{I} / \mathrm{T}$ in declarative main clauses, and from I/T to $C$ in yes/no-questions and wh-questions, as well as in certain other sentence types. In such structures, the verb becomes the second constituent, and English is thus said to display so-called residual V2 (Rizzi, 1996).

Differences in verb movement have consequences for the surface word order of the three languages. In French, placement of the finite verb in I/T makes it the third constituent in non-subject initial topicalized structures (1a) and the second constituent in structures with a sentence adverbial (2a). In English, lexical verbs remain in situ and thus appear as the third constituent for both topicalized structures and sentences with sentence adverbials $(1 b, 2 b)$. Since Norwegian has obligatory movement of finite verbs to $C$ in main clauses, the finite verb is the second constituent in both topicalized structures (1c) and sentences with sentence 
adverbials (2c). ${ }^{1}$
a. Le lundi, je
mange du poisson.
(Topicalized element,
b. On Mondays, I
eat
fish
c. På mandager spiser jeg
fisk. subject, verb)

(2)
a. $\underline{\mathrm{J}}$
mange
toujours
à 7 heures.
(Sentence adverbial,
b. I
always
eat
c. Jeg
spiser alltid
at 7 o'clock.
klokka 7.

\section{[2.2] Transfer in third language acquisition}

An important question in L2 acquisition research is that of the influence of the L1, often described as (L1) transfer. Such influence has been investigated for all domains of language, including syntax, and research has demonstrated systematic patterns of transfer of linguistic representations from L1 into the L2 (cf. Schwartz \& Sprouse, 1996; White, 2003). Whether such transfer entails that the entire L1 grammar transfers to the L2 (Schwartz \& Sprouse, 1996), or whether there is merely potential for transfer for all or a subset of the L1 grammar (Westergaard, 2019) is still a matter of debate.

An important question is what happens when the language being acquired is an L3 rather than an L2, which entails that the learner has more than one previous language system as a potential source of transfer (e.g., Williams \& Hammarberg, 1998). Important research questions in this area are whether only one of the previously acquired languages constitutes the initial state of the L3, and what determines the influence of L1 and L2, respectively, in the initial stages and throughout L3 acquisition (see e.g., Bardel, 2019; Puig-Mayenco, González Alonso \& Rothman, 2020; Slabakova, 2017 for overviews).

One possibility is that the $\mathrm{L} 1$ is the main source of transfer, and some studies have indeed found evidence that this is the case (Hermas, 2010; Jin, 2009; Na Ranong \& Leung, 2009). However, others have found the L2 to have a privileged status for transfer in L3 acquisition (Bardel \& Falk, 2007; Falk \& Bardel, 2011). Bardel and Falk (2012) argue that L2 and L3 learned after a certain age share a similar status regarding metalinguistic knowledge and that L2 and L3 are acquired, and thus stored, in a similar manner in the mind. According to the authors, this reflects that, compared to the L1, L2 relies more heavily on the declarative rather than the procedural memory system (cf. Paradis, 2009; Ullman, 2001). A third possibility is that language similarity rather than order of acquisition decides which of the previously learned languages constitutes the source of

[1] See however Westergaard, Lohndal \& Alexiadou (2019). 
transfer, at least in the initial stages (e.g., Rothman, 2010). A final possibility is that both previously learned languages may influence the L3 during acquisition, either in that different structures are transferred from different languages (e.g., Flynn, Foley \& Vinnitskaya, 2004; Slabakova, 2017), that one and the same structure may be influenced by both prior languages (Westergaard et al., 2017), or that influence from the respective prior languages may depend on L2 and L3 proficiency (Sánchez, 2020; Stadt, Hulk \& Sleeman, 2016, 2018a,b). A further complicating factor when discussing transfer from the L2 is the fact that transfer must happen from the learner's L2 grammar such as it is. Presumably, a structure must have been acquired in the L2 in order to be transferrable at all, since a learner "could not possibly transfer that which has not yet been acquired" (Rothman, Gonzáles Alonso \& Puig-Mayenco, 2019, p. 209).

There is still no consensus on what factors determine the influence of the respective prior languages in L3 acquisition. In the case of foreign language learning, including French, in Norwegian schools, it is important to learn more about the role of previously learned languages in order to understand what impact the $\mathrm{L} 1$, the L2, and any other prior languages may have on the acquisition process in terms of benefits or added challenges.

\section{[2.3] Previous research on (transfer in) the acquisition of verb placement}

L2 learners seem to struggle when verb placement in the L2 diverges from that of the L1, at least initially. Evidence has been found that L1 English speakers have problems with acquiring verb movement in L2 French (Ayoun, 1999; Hawkins, Towell \& Bazergui, 1993), and, conversely, L1 French speakers have been found to allow non-target verb movement in L2 English (e.g., White, 1990/1991, Trahey \& White, 1993). Furthermore, speakers of L1s with V2 tend to over-accept or produce V2 in L2 English (Westergaard, 2002, 2003; Rankin, 2012). In contrast, speakers of L1s without V2 learning a language with V2 have been found not to produce V2 with finite verbs (cf. Schimke \& Dimroth, 2018).

In L3 acquisition, Håkansson et al. (2002) discovered that L1 Swedish learners do not start out producing V2 in L3 German, even though both are V2 languages. Bohnacker (2006), however, found that L1 Swedish speakers with no knowledge of English acquiring German as an L2 did produce V2 from the start, while knowledge of English seemed to impede such facilitative transfer from L1 to L3. Bardel and Falk (2007) investigated transfer of (non-)V2 among learners whose L1 and L3 were V2 languages (L1 Swedish/L3 Dutch and vice versa) with English as L2 and also identified transfer of non-V2 from L2 English. Stadt et al. (2016, 2018a,b) found evidence of both transfer of V2 from L1 Dutch and transfer of non-V2 from L2 English in speakers of L3 French in the same sentence types as 
those investigated in the present study. In Stadt et al.'s studies, transfer from L1 was associated with the earliest stages of L3 acquisition, while transfer from L2 English became more pronounced later in the acquisition process and was also associated with more exposure to and higher competence in L2 English. A recent study of the same structure types in the L3 acquisition of German by L1 speakers of Norwegian with English as L2 found no clear evidence indication of transfer from neither L1 nor L2 (Dahl, Listhaug \& Busterud, 2020).

In sum, it is not clear how prior languages influence the acquisition of verb placement in L3. The current study seeks to fill this knowledge gap.

\section{[3] The present study}

The present study of the L3 acquisition of verb placement in French in learners with L1 Norwegian and L2 English sought to answer the following research questions:

(i) To what extent does (lexical) verb placement in L1 Norwegian and L2 English influence verb placement in L3 French?

(ii) Does the partially overlapping surface word order with French in each prior language pose problems in the acquisition of verb placement in French?

(iii) Is higher proficiency in L2 associated with more evidence of transfer from the $\mathrm{L} 2$ into the $\mathrm{L} 3$ ?

\section{[3.1] Methods and materials}

We investigated high-school students (age 16-17, $\mathrm{n}=112$ ) and university students (mean age $21, \mathrm{n}=12$ ). The high school students were in their first, second, forth, or fifth year of French studies ${ }^{2}$, see table 2. The participants completed acceptability judgment tests in both L2 English and L3 French, with sentence types like (1) and (2) above. There were 24 target sentences distributed across four conditions with six tokens for each condition: Verb in second position (verb2) and in third position (verb-3) in topicalized structures, and verb-2 and verb-3 in subject-initial declaratives with sentence adverbials, see Table 1. In addition, the test included 12 grammatical and 12 ungrammatical filler sentences. Each sentence was judged on a four-point Likert scale where an emoticon at each end indicated that 1 represented an unacceptable sentence and 4 an acceptable sentence. Participants first completed the test in L3 and then in L2 roughly two

[2] High school students were in year 11 or 12 of school, and since foreign language teaching in Norway starts in either year 8 or year 11, this means that none were in their third year of French studies. 
weeks later.

\begin{tabular}{lll}
\hline Sentence type & French & English \\
\hline Topicalization, verb-2 & *Le matin boit Tina & *In the morning drinks Tina \\
& du lait. & milk. \\
Topicalization, verb-3 & $\begin{array}{l}\text { Le matin, Tina boit du } \\
\text { lait. }\end{array}$ & $\begin{array}{l}\text { In the morning, Tina drinks } \\
\text { milk. }\end{array}$ \\
Sentence adverbial, verb-2 & $\begin{array}{l}\text { J'écoute souvent de la } \\
\text { musique. }\end{array}$ & *I listen often to music. \\
Sentence adverbial, verb-3 & *Je souvent écoute de & I often listen to music. \\
& la musique. & \\
\hline
\end{tabular}

TABLE 1. EXAMPLES OF TEST ITEMS

Background data were collected about age, gender, relevant diagnoses, L1 background, years of exposure to L2 and L3, and L2 and L3 proficiency (indicated by the last term grade and self-ratings). Only participants with Norwegian as their only L1 who did not have self-rated competence in an additional language beyond L1 Norwegian and L2 English higher than that of L3 French, and who did not report any diagnoses which may influence acquisition (e.g., autism) were included. The project was registered with the Norwegian Centre for Research Data, and participation was voluntary.

\section{[4] Results}

In this section we first present the results from the L3 French test, and then from the L2 English test. Data were analyzed using Tibco Statistica 13.5.0.

table 2 shows mean scores and standard deviations on the L3 French test sentences. High mean scores (maximum $=4$ ) imply high levels of acceptance. We see a general trend where mean scores increase for grammatical and decrease for ungrammatical sentences with more years of instruction. 


\begin{tabular}{cccccccccc}
\hline & \multicolumn{4}{c}{ Verb-2 } & \multicolumn{4}{c}{ Verb-3 } \\
Years of & \multicolumn{4}{c}{ Topicalization } & \multicolumn{2}{c}{$\begin{array}{c}\text { Sdverbial } \\
\text { adventence }\end{array}$} \\
French & $\mathbf{n}$ & Mean & SD & Mean & SD & Mean & SD & Mean & SD \\
\hline 1 & 9 & 2.22 & 0.61 & 2.66 & 0.33 & 2.93 & 0.31 & 2.69 & 0.38 \\
2 & 18 & 2.62 & 0.43 & 2.80 & 0.49 & 2.76 & 0.48 & 2.99 & 0.41 \\
4 & 40 & 2.14 & 0.57 & 3.06 & 0.36 & 3.22 & 0.38 & 2.68 & 0.43 \\
5 & 45 & 2.23 & 0.55 & 2.97 & 0.59 & 2.89 & 0.48 & 2.66 & 0.49 \\
Uni & 12 & 1.67 & 0.53 & 3.51 & 0.47 & 3.35 & 0.40 & 2.16 & 0.70 \\
\hline
\end{tabular}

TABLE 2. MEAN SCORES AND STANDARD DEVIATIONS FOR TEST SENTENCES IN L3 FRENCH PER EXPERIMENTAL GROUP

Results were compared in a 2 (verb placement; verb-2 vs verb-3) x 2 (Sentence type; Topicalization vs Sentence adverbial) repeated measures ANOVA with years of French instruction as the grouping variable. Results showed a main effect of verb placement $\left(F(1,119)=42.21, p<.0001, \eta_{p}{ }^{2}=.26\right)$, where sentences with verb-2 received lower scores $($ mean $=2.59, \mathrm{SE}=0.06)$ than sentences with verb-3 (mean=2.83, $\mathrm{SE}=0.06$ ). Furthermore, there was a main effect of sentence type $\left(F(1,119)=31.26, p<.0001, \eta_{\mathrm{p}}{ }^{2}=.21\right)$, where sentences with topicalizations received lower scores overall (mean $=2.60, \mathrm{SE}=0.06)$ than sentences with a sentence adverbial (mean $=2.82, \mathrm{SE}=0.06$ ). Finally, there was an interaction effect of verb placement and sentence type $\left(F(1,119)=134.70, p<.0001, \eta_{p}{ }^{2}=.53\right)$, where ungrammatical sentences with sentence adverbials (i.e., verb-3) received overall higher judgment scores (mean $=2.63, \mathrm{SE}=.05$ ) than ungrammatical sentences with topicalizations (i.e., verb-2) $($ mean $=2.17, \mathrm{SE}=.06)$. This interaction was in turn modulated by group $\left(F(4,119)=20.20, p<.0001, \eta_{\mathrm{p}}{ }^{2}=.40\right)$, see FIGURE 1 . 
L3 French: Test Items
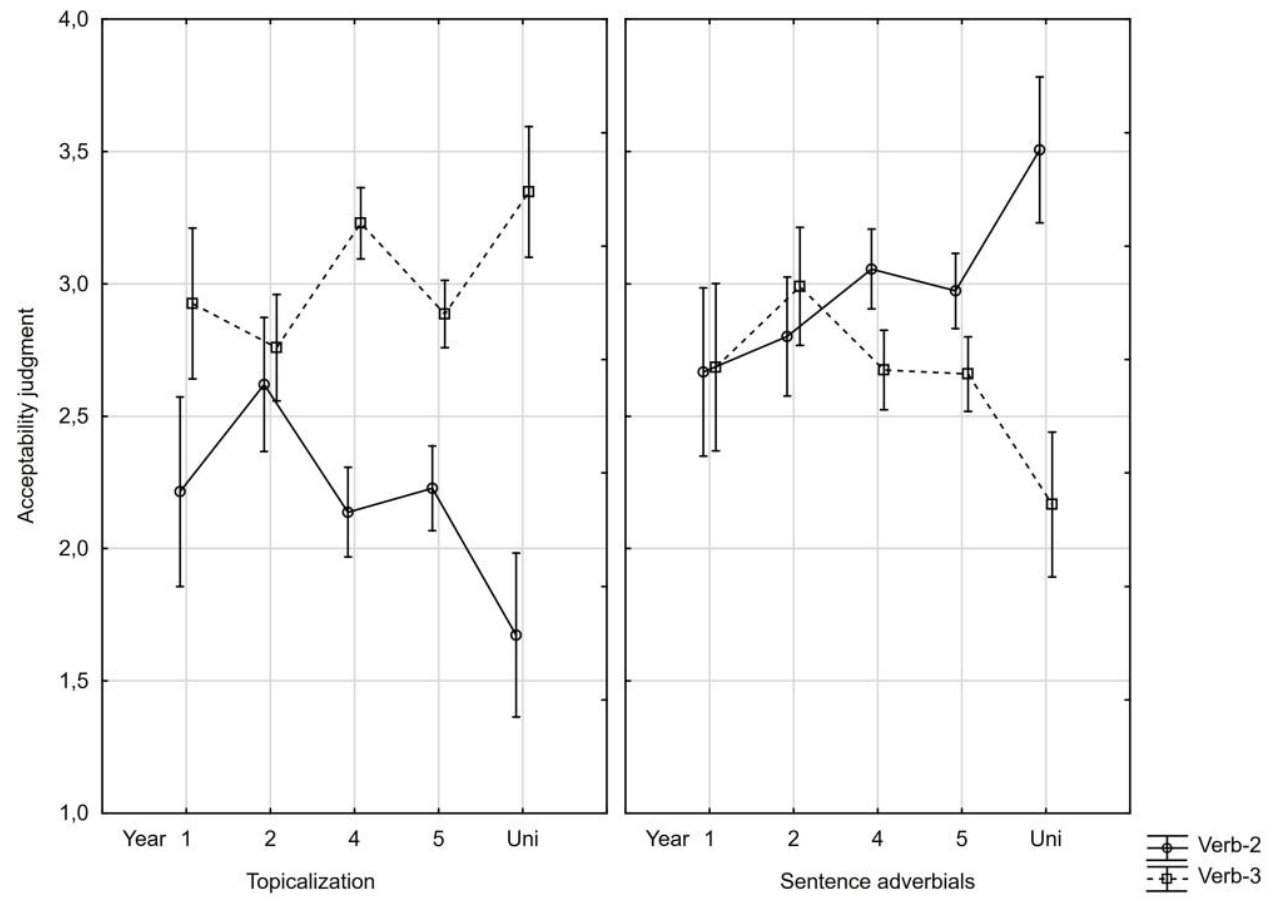

FIGURE 1: THREE-WAY INTERACTION OF VERB PLACEMENT, SENTENCE TYPE, AND PARTICIPANT GROUP IN L3 FRENCH. VERTICAL BARS DENOTE 95\% CONFIDENCE INTERVALS.

To break down the three-way interaction of verb placement, sentence type and participant group, Tukey HSD post-hocs were conducted. They revealed significant differences in judgments on grammatical verb-3 vs ungrammatical verb-2 with topicalizations in learners in Year $4(p<.001)$, Year $5(p<.001)$, and at university $(p<.001)$, but not in learners in Years 1 and 2 (see table 2 for means). For sentences with sentence adverbials, there were significant differences in judgments on grammatical verb- 2 vs ungrammatical verb- 3 only in learners at university level $(p<.001)$. This indicates that learners started to discriminate between the two word orders in topicalized structures earlier than in sentences with a sentence adverbial.

In the individual learner groups there were no significant differences between judgments on the two grammatical structures, i.e., verb-3 with topicalizations and verb- 2 with sentence adverbials. For the ungrammatical sentences, on the other hand, students in Years 4 and 5 judged sentences with topicalizations significantly lower than sentences with sentence adverbials (Year $4 p=.0005$, Year $5 p=.007$ ), i.e., they more consistently rejected the former. These are the same 
two learner groups which discriminated between grammatical and ungrammatical word orders for topicalized structures but not for sentence adverbials. We return to this finding in the Discussion. Overall, learners in Years 1 and 2 do not distinguish between grammatical and ungrammatical sentences for either sentence type. Learners in Years 4 and 5 distinguish between grammatical and ungrammatical sentences with topicalizations but fail to reject ungrammatical sentences with sentence adverbials. The university students clearly distinguish between grammatical and ungrammatical sentences of either type.

We turn next to the results from the L2 English test. table 3 shows mean scores and standard deviations for English test sentences. Note that group labels refer to years of instruction in L3 French, not in English.

\begin{tabular}{cccccccccc}
\hline & \multicolumn{4}{c}{ Verb-2 } & \multicolumn{4}{c}{ Verb-3 } \\
Years of & \multicolumn{4}{c}{ Topicalization } & \multicolumn{2}{c}{$\begin{array}{c}\text { Sentence } \\
\text { adverbial }\end{array}$} & \multicolumn{2}{c}{ Topicalization } & \multicolumn{2}{c}{$\begin{array}{c}\text { adverbial } \\
\text { French }\end{array}$} & $\mathbf{n}$ & Mean & SD & Mean & SD & Mean & SD & Mean & SD \\
\hline 1 & 9 & 1.42 & 0.53 & 1.93 & 0.76 & 3.20 & 0.63 & 3.27 & 0.53 \\
2 & 18 & 1.46 & 0.35 & 2.02 & 0.65 & 3.21 & 0.43 & 3.25 & 0.37 \\
4 & 40 & 1.64 & 0.39 & 2.01 & 0.45 & 3.39 & 0.35 & 3.51 & 0.36 \\
5 & 45 & 1.45 & 0.43 & 1.82 & 0.48 & 3.37 & 0.44 & 3.32 & 0.37 \\
Uni & 12 & 1.78 & 0.65 & 1.88 & 0.70 & 3.58 & 0.29 & 3.61 & 0.41 \\
\hline
\end{tabular}

TABLE 3. MEAN SCORES AND STANDARD DEVIATIONS FOR TEST SENTENCES IN L2 ENGLISH PER EXPERIMENTAL GROUP. 
Results were compared in a 2 (verb placement; verb-2 vs verb-3) x 2 (Sentence type; Topicalization vs Sentence adverbial) repeated measures ANOVA with years of French instruction as the grouping variable. There were no (interaction) effects of learner group, which was expected, given that groups correspond to years of French, not English instruction. Results showed a main effect of verb placement $\left(F(1,119)=1018.63, p<.00001, \eta_{p}{ }^{2}=.90\right)$, where sentences with verb-2 (mean=1.74, SE $=0.07)$ received significantly lower scores than sentences with verb-3 (mean=3.37, $\mathrm{SE}=0.05$ ). There was also a main effect of sentence type $\left(F(1,119)=44.38, \quad p<.00001, \quad \eta_{\mathrm{p}}{ }^{2}=.27\right) \quad$ where sentences with topicalizations (mean $=2.45, \mathrm{SE}=0.05$ ) received lower scores than sentences with sentence adverbials (mean=2.66, $\mathrm{SE}=0.06$ ). Importantly, there was an interaction effect of verb placement and sentence type $\left(F(1,119)=25.95, p<.00001, \eta_{\mathrm{p}}{ }^{2}=.18\right)$, see FIGURE 2 .

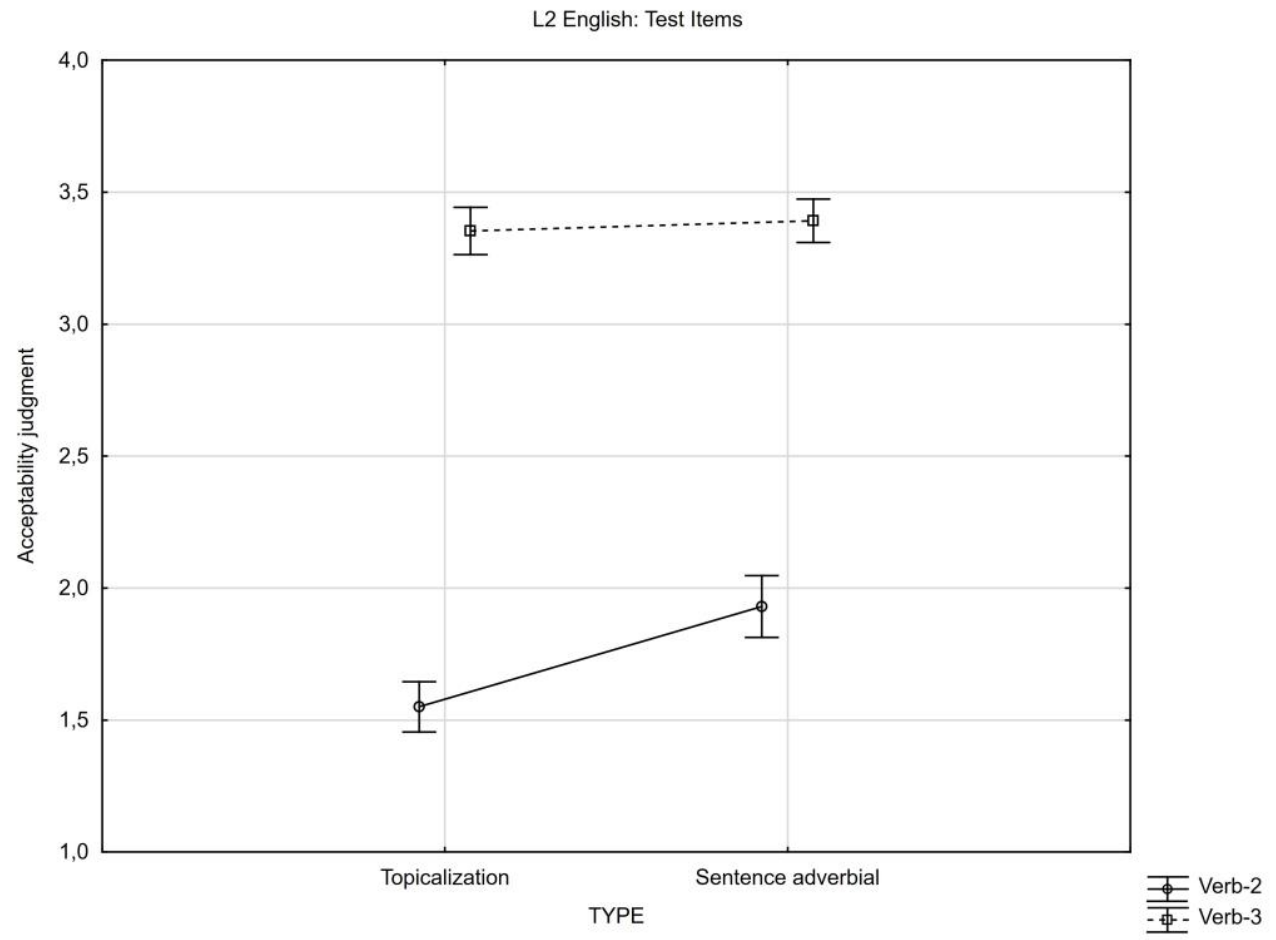

FIGURE 2. INTERACTION EFFECT OF VERB PLACEMENT AND SENTENCE TYPE IN L2 ENGLISH. VERTICAL BARS DENOTE 95\% CONFIDENCE INTERVALS.

Tukey HSD post-hocs were conducted to break down the interaction. Results showed no significant differences in scores for the two sentence types for grammatical sentences (i.e., verb-3), whereas ungrammatical sentences (i.e., verb-2) 
with sentence adverbials (mean $=1.93, \mathrm{SE}=0.06$ ) received significantly higher scores than ungrammatical sentences with topicalizations (mean=1.55, $\mathrm{SE}=0.05$ ). This indicates that while participants generally accepted the grammatical and rejected the ungrammatical sentences, they were less consistent in rejecting ungrammatical sentences with sentence adverbials compared to ungrammatical topicalized constructions.

Together, results for the two tests indicated greater insecurity about judgments for sentences with sentence adverbials compared to topicalizations in both L2 English and L3 French.

In order to investigate the relationship between the two structures within and across the L2 and the L3, we calculated the degree to which participants discriminated between the grammatical and the ungrammatical word orders. This discrimination score was calculated by subtracting the mean score for the ungrammatical from that of the grammatical word order for each participant, for each sentence type, and in each language. The maximum possible discrimination score was thus 3, indicating that the participant gave a mean score of 4 to the grammatical and 1 to the ungrammatical structure, whereas a negative value indicated higher scores to the ungrammatical than the grammatical structure. Higher scores thus indicate clearer discrimination between grammatical and ungrammatical word orders. table 4 shows mean discrimination scores and standard deviations for each experimental group.

\begin{tabular}{cccccccccc}
\hline & \multicolumn{4}{c}{ French } & \multicolumn{4}{c}{ English } \\
Years of & \multicolumn{4}{c}{ Topicalization } & \multicolumn{2}{c}{$\begin{array}{c}\text { Sentence } \\
\text { adverbial }\end{array}$} & \multicolumn{2}{c}{ Topicalization } & \multicolumn{2}{c}{$\begin{array}{c}\text { Sentence } \\
\text { adverbial } \\
\text { French }\end{array}$} & $\mathbf{n}$ & Mean & SD & Mean & SD & Mean & SD & Mean & SD \\
\hline 1 & 9 & 0.71 & 0.36 & -0.02 & 0.36 & 1.78 & 0.69 & 1.34 & 0.79 \\
2 & 18 & 0.14 & 0.55 & -0.19 & 0.47 & 1.76 & 0.50 & 1.23 & 0.63 \\
4 & 40 & 1.09 & 0.64 & 0.38 & 0.50 & 1.74 & 0.43 & 1.50 & 0.51 \\
5 & 45 & 0.66 & 0.70 & 0.31 & 0.61 & 1.93 & 0.55 & 1.50 & 0.54 \\
Uni & 12 & 1.67 & 0.39 & 1.34 & 0.80 & 1.18 & 0.69 & 1.73 & 0.75 \\
\hline
\end{tabular}

TABLE 4. MEAN DISCRIMINATION SCORES AND STANDARD DEVIATIONS PER EXPERIMENTAL GROUP.

Correlation analyses were performed with Pearson's $r$ on discrimination scores across structure types and languages. We looked both at data from all groups combined and from each experimental group separately, given that transfer from L1 vs L2 can be expected to vary over the course of L3 acquisition. 
In L3 French, results for all participant groups combined showed a significant positive correlation between discrimination scores on the two structures (i.e., topicalizations vs sentence adverbials) $(r=.51, p<.00001)$. However, the relationship differed across groups, with the correlation being significant only for participants in Year $4(r=.41, p<.01)$ and Year $5(r=.36, p<.05)$. In L2 English, there was also a significant positive correlation between scores on the two structure types $(r=.39, p=<.001)$ for all groups combined. Analyses for separate experimental groups yielded a positive correlation only in Year $5(r=.48, p=.001)$. Overall, for both languages, the results showed that participants who discriminated more between the grammatical and the ungrammatical word order did so in both sentence types.

Comparison of results across languages (i.e., L3 French vs L2 English) showed no significant correlations between discrimination scores on sentences with topicalizations. This may reflect ceiling effects for this structure type in English. For sentences with sentence adverbials, however, there was a positive correlation for all groups combined $(r=.24, p<.01)$. Looking at the individual groups, the correlation was only significant in Year $4(r=.45, p<.01)$. This indicates that participants who discriminated more clearly between grammatical and ungrammatical word orders with sentence adverbials in L2 English did so also in L3 French.

We investigated the relationship between proficiency in the L2 and performance in L3 by correlating L3 discrimination scores with our two measures of proficiency in L2 English: self-reported proficiency level and term grade. There were no significant correlations with self-reported proficiency in English and discrimination scores on either sentence type in L3 French, probably due to ceiling effects; $75 \%$ of the participants rated their English proficiency to be 5 or above on our 6-point scale. There was, however, a positive correlation between reported grade in English and discrimination scores both for topicalized constructions $(r=.25 p<.01)$ and sentences with sentence adverbials $(r=.30 p<.001)$, indicating that higher general proficiency in English was associated with clearer discrimination between grammatical and ungrammatical word orders in L3 French.

Taken together, results showed that participants in the first two years of learning French showed no clear preference for verb-2 or verb-3 for either structure in French. In later years, participants were more target-like in judgments of topicalizations than of sentences with sentence adverbials. Furthermore, there were positive correlations between both performance and proficiency in L2 English and performance in L3 French. 


\section{[5] Discussion}

Our first research question asked to what extent we see an influence of Norwegian and/or English in the participants' judgments of verb placement in L3 French. We found no clear evidence that our participants had fully transferred the grammar of neither L1 Norwegian nor L2 English at the earliest stages of acquisition. Participants in Years 1 and 2 showed an indeterminacy which probably reflected insecurity rather than transfer per se. However, this insecurity may in part stem from some form of cross-linguistic influence from the prior languages. While there were no significant differences, participants in Years 1 and 2 gave topicalized structures with verb-3 higher scores than topicalized structures with verb-2. This may reflect emergent acquisition of the French structure but could also have been facilitated by influence from L2 English. However, since topicalized constructions with V2 entail movement of the finite verb across the subject to $C$, the relative acceptance of these ungrammatical structures suggests that participants in Years 1 and 2 are "uneconomical" in the sense that they allow (or at least do not clearly reject) verb movement for which they have no evidence in the L3 input. Movement to $C$ is argued to depend on processing procedures that are not available at early stages of acquisition (cf. Håkansson et al., 2002), and as far as we know, there is no evidence that L1 speakers of non-V2 languages overuse this type of movement in non-V2 L2s. It thus seems most likely that the low rejection of topicalizations with verb-2 in our participants is due to influence from Norwegian. For these structures, V2 is not acceptable in English and does not seem to be part of our participants' L2 grammar, and therefore cannot be a result of $\mathrm{L} 2$ transfer.

For placement of sentence adverbials, on the other hand, Norwegian and French have the same surface word order. It is striking that participants are even more uncertain about these structures than about topicalizations. In fact, in Year 1 and 2, students preferred the ungrammatical verb-3 word order over the grammatical verb- 2 word order, as evidenced by the negative mean discrimination scores in both these groups. The question is whether this uncertainty is due to influence from English, and, in particular, responding to our second research question, whether the uncertainty about verb placement relative to sentence adverbial placement may be a result of influence from Norwegian and English combined: Upon realizing that French and English are more similar in other structures, such as topicalizations, the participants may have generalized this similarity to also hold for constructions with sentence adverbials.

It is of course possible that the difference in performance for sentences with sentence adverbials compared to topicalizations simply implies that adverbial placement is generally more difficult. Adverbial distribution has for example 
been argued to be an unreliable cue in the acquisition of verb placement in L1 (Lightfoot \& Hornstein, 1994).

The ideal testbed for establishing whether insecurity about verb placement relative to adverbials in L3 French is in fact a result of influence from English would be to compare our results to a group of L1 Norwegian L2 French learners, where there is no possibility of transfer from English. Such a group, however, is virtually impossible to find, because of the status of English in Norway. However, comparison to other studies may be enlightening. Results from a very similar study to the present one, but on the L3 acquisition of German in L1 Norwegian L2 English speakers (Dahl et al., 2020), suggest that verb placement relative to sentence adverbials is not uniformly more difficult than in topicalizations. That study investigated the same two structure types as the current study and found more target-like judgments for sentence adverbials than for topicalizations in L3 German. Similarly, Stadt et al. (2020) found that adverbial placement in L3 German was more target-like than in L3 French in two proficiency-matched groups of L1 Dutch L2 English speakers. These studies indicate that word order relative to sentence adverbials may be especially problematic for L3 French in L1 speakers of V2 languages with English as an L2. This would support the hypothesis that partial (surface) word order overlap resulting in cross-linguistic influence from English plays a role.

Regarding our third research question, it seems likely that the non-target judgments on sentence adverbials in the current study are a result of transfer from English. Based on Stadt et al. (2016, 2018a,b), who investigated relatively similar learners and found that higher proficiency in L2 English was associated with more evidence of transfer from the L2, the prediction would be that this transfer will be most prominent for participants with higher proficiency in English. However, in our results we saw a positive correlation between grades in English and discrimination scores in L3 French for both topicalizations and sentences with sentence adverbials. These results are in line with findings in Dahl et al. (2020), where higher L2 English proficiency was associated with more target-like performance in L3 German and thus less evidence of L2 transfer. It thus seems that our results are in line with studies finding more evidence of L2 transfer at lower L2 proficiency levels (e.g., Sánchez, 2020).

As pointed out in section 2.2, we assume that a particular structure must have been acquired in the L2 for it to be transferrable to the L3. One might also expect that more consistent target-like judgments, possibly reflecting a more stable L2 representation, might predict more prominent L2 transfer. Although our participants clearly accepted the grammatical word order for English sentences with sentence adverbials, not all of them consistently rejected non-target like (verb- 
2) word order. Yet, the positive correlation between discrimination scores for this structure in L2 English and L3 French supports the idea that participants with less clear intuitions for the structure in L2 English were more prone to transfer the English word order into the L3. This is in line with the findings in Sánchez (2020) that high syntactic proficiency for a specific structure in L2 is not a prerequisite for its transfer to the L3.

In sum, both with respect to general L2 proficiency and to knowledge of particular structures, we see that higher proficiency in the L2 correlates with more target-like performance in the L3. The difference between our results and those of Stadt et al. (2016, 2018a,b) may stem from the specific learning context for L2 and L3. All participants in our study had been learning English for approximately the same number of years, and in a similar context. Learner-internal factors such as language learning abilities, meta-linguistic knowledge, learning strategies, and motivation are therefore likely to be the main explanations for differences in L2 proficiency and may affect L3 acquisition as well. Arguably, learners with less strong language learning abilities and/or strategies and motivation may also be less sensitive to the relevant difference between L2 English and L3 French and may therefore be more prone to misanalysis due to L2 English. In Stadt et al. $(2016,2018 \mathrm{a}, \mathrm{b})$, on the other hand, the participants' English proficiency depended on external circumstances, i.e., whether they were in the immersion track or for how many years they had been learning English. The individual differences relevant in the present study were probably less influential for the results in Stadt et al.'s studies. Bardel and Falk (2012) hypothesize that L2 transfer will be less prominent in speakers with very high L2 proficiency. It is not obvious that the L2 Status Factor model is relevant for L2 English in our study, given the low L2 starting age and general high proficiency. However, it is possible that, compared to those with higher L2 proficiency, our lower proficiency L2 participants treated both languages more similarly as foreign languages and thus were more prone transfer between the two (often referred to as "interlanguage transfer", cf. De Angelis \& Selinker (2001)), and that this partially explains our findings.

\section{[6] Conclusion}

We do not see conclusive evidence of transfer from neither L1 Norwegian nor L2 English in our results. In particular, it is difficult to argue that we see a privileged status for either language as a source of transfer. We do, however, see indications that both languages may possibly influence L3 French. Specifically, we argue that the partial overlap in surface word order with French in both L1 and L2 may po- 
tentially cause transfer of a non-target structure into L3. Importantly, and somewhat surprisingly, higher L2 proficiency seems to be associated with less L2 transfer, arguably because of the common individual factors underlying both $\mathrm{L} 2$ and $\mathrm{L} 3$ acquisition.

While we cannot conclude definitively that our results demonstrate transfer from L2 English into L3 French, our data do indicate that some form of L2 influence may contribute to shaping Norwegian learners' intuitions about L3 French. This underlines the importance of keeping in mind the current role of English in Norway; the study of other additional languages, such as French, must consider that these additional languages are never second languages. In Norway, English will always be part of the participants' linguistic background and must therefore be taken into account.

\section{REFERENCES}

Ayoun, Dalila. 1999. Verb movement in French L2 acquisition. Bilingualism: Language and Cognition 2(2). 103-125.

Bardel, Camilla. 2019. Syntactic transfer in L3 learning. What do models and results tell us about learning and teaching a third language? In M. Juncal Gutierrez-Mangado, Maria Martínez Adrián M. \& Francisco Gallardo Del Puerto (eds.), Cross-Linguistic Influence: From Empirical Evidence to Classroom Practice, chap. 6, 101-120. Springer.

Bardel, Camilla \& Ylva Falk. 2007. The role of the second language in third language acquisition: The case of Germanic syntax. Second Language Research 23(4). 459-484.

Bardel, Camilla \& Ylva Falk. 2012. The L2 status factor and the declarative/procedural distinction. In Jennifer Cabrelli, Suzanne Flynn \& Jason Rothman (eds.), Third language acquisition in adulthood, 61-78. John Benjamins.

Bohnacker, Ute. 2006. When Swedes begin to learn German: From V2 to V2. Second Language Research 22(4). 443-486.

Dahl, Anne, Kjersti Faldet Listhaug \& Guro Busterud. 2020. Manuscript accepted for publication. The role of L1 Norwegian and L2 English in the acquisition of verb placement in L3 German.

De Angelis, Gessica \& Larry Selinker. 2001. Interlanguage, transfer and competing linguistic systems in the multilingual mind. In Jasone Cenoz, Britta Hufeisen \& Ulrike Jessner (eds), Cross-linguistic influence in third language acquisition: Psy- 
cholinguistic perspectives. 42-58. Multilingual Matters.

Falk, Ylva \& Camilla Bardel. 2011. Object pronouns in German L3 syntax: Evidence for the L2 status factor. Second Language Research 27(1). 59-82.

Flynn, Susan, Claire Foley \& Inna Vinnitskaya. 2004. The Cumulative-Enhancement Model for language acquisition: Comparing adults' and children's patterns of development in first, second and third language acquisition of relative clauses. International Journal of Multilingualism 1(1). 3-16.

Hawkins, Roger, Richard Towell \& Nives Bazergui. 1993. Universal Grammar and the acquisition of French verb movement by native speakers of English. Second Language Research 9(3). 189-233.

Hermas, Abdelkader. 2010. Language acquisition as computational resetting: verb movement in L3 initial state. International Journal of Multilingualism 7(4). 343362.

Holmberg, Anders \& Christer Platzack. 1995. The role of inflection in Scandinavian syntax. Oxford University Press.

Håkansson, Gisela, Manfred Pienemann \& Susan Sayehli. 2002. Transfer and typological proximity in the context of second language processing. Second Language Research 18(3). 250-273.

Jin, Fufen 2009. Third language acquisition of Norwegian objects: Interlanguage, transfer or L1 Influence? Third language acquisition and Universal Grammar. In Yan-kit Ingrid Leung (ed.), Third language acquisition and Universal Grammar, chap. 7, 144-161. Multilingual Matters.

Lightfoot, David \& Norbert Hornstein. 1994. Verb movement: an introduction. In David Lightfoot \& Norbert Hornstein (eds.), Verb movement, chap. 1, 1-18. Cambridge University Press.

Na Ranong, Sirirat \& Yan-kit Ingrid Leung. 2009. Null Objects in L1 Thai-L2 English-Chinese: An empiricist take on a theoretical problem. In Yan-kit Ingrid Leung (ed.), Third language acquisition and Universal Grammar, chap. 8, 162-191. Multilingual Matters.

Paradis, Michel. 2009. Declarative and procedural determinants of second languages. John Benjamins. 
Pollock, Jean-Yves. 1989. Verb movement, Universal Grammar, and the structure of IP. Linguistic Inquiry 20(3). 365-424.

Puig-Mayenco, Eloi, Jorge González Alonso and Jason Rothman. 2020. A systematic review of transfer studies in third language acquisition. Second Language Research 36(1). 31-64.

Rankin, Tom 2012. The transfer of V2: inversion and negation in German and Dutch learners of English. International Journal of Bilingualism 16(1). 139-158.

Rizzi, Luigi 1996. Residual verb second and the Wh-criterion. In Adriana Belleti \& Luigi Rizzi (eds.), Parameters and Functional Heads: Essays in Comparative Syntax, 62-90. Oxford University Press.

Roberts, Ian. 2001. Head movement. In Mark Baltin \& Chris Collins (eds.), The handbook of contemporary syntactic theory, 112-147. Blackwell.

Rothman, Jason. 2010. L3 syntactic transfer selectivity and typological determinacy: The typological primacy model. Second Language Research 27(1). 107127.

Rothman, Jason, Jorge Gonzáles Alonso \& Eloi Puig-Mayenco. 2019. Third language acquisition and linguistic transfer. Cambridge University Press.

Sánchez, Laura. 2020. From L2 to L3, verbs getting into place: A study on interlanguage transfer and L2 syntactic proficiency. In Camilla Bardel \& Laura Sánchez (eds.), Third language acquisition. Age, proficiency and multilingualism. (Eurosla Studies 3). 209-236. Language Science Press.

Schimke, Sarah \& Christine Dimroth. 2017. The influence of finiteness and light ness on verb placement in L2 German: Comparing child and adult learners. Second Language Research 34(2). 1-28.

Schwartz, Bonnie D. \& Rex A. Sprouse. 1996. L2 cognitive states and the Full Transfer/Full Access model. Second Language Research 12(1). 40-72.

Slabakova, Roumyana. 2017. The scalpel model of third language acquisition. International Journal of Bilingualism 21(6). 651-665.

Stadt, Rosalinde, Aafke Hulk \& Petra Sleeman. 2016. The influence of L2 English and immersion education on L3 French in the Netherlands. Linguistics in the Netherlands 33(1). 152-165. 
Stadt, Rosalinde, Aafke Hulk \& Petra Sleeman. 2018a. The influence of L1 Dutch and L2 English on L3 French: A longitudinal study. Journal of the European Second Language Association 2(1). 63-71.

Stadt, Rosalinde, Aafke Hulk \& Petra Sleeman. 2018b. The role of L2 exposure in L3A: A comparative study between third and fourth year secondary school students in the Netherlands. In Janine Berns, Haike Jacobs \& Dominique Nouveau (eds.), Romance Languages and Linguistic Theory: Selected papers from 'Going Romance' 29, Nijmegen. 279-296. John Benjamins.

Stadt, Rosalinde, Aafke Hulk \& Petra Sleeman. 2020. L2 influence in L3 acquisition. In Andreas Trotzke, \& Tanja Kupisch (eds.), Formal linguistics and language education. New empirical perspectives, 203-221. Springer.

Trahey, Martha \& Lydia White. 1993. Positive evidence and preemption in the second language classroom. Studies in Second Language Acquisition 15(2). 181204.

Ullman, Michael T. 2001. The neural basis of lexicon and grammar in first and second language: the declarative/procedural model. Bilingualism: Language and Cognition 4(2). 105-122.

Westergaard, Marit. 2002. Minimal input in L2 acquisition: How Norwegian children learn English word order. Acta Didactica 3. 199 -218.

Westergaard, Marit. 2003. Unlearning V2: Transfer, markedness, and the importance of input cues in the acquisition of word order in English by Norwegian children. EUROSLA Yearbook 3. 77-101.

Westergaard, Marit. 2009. Usage-based vs. rule-based learning: the acquisition of word order in wh-questions in English and Norwegian. Journal of Child Language 36(5). 1023-1051.

Westergaard, Marit. 2019. Microvariation in multilingual situations: The importance of property-by-property acquisition. Second Language Research, Online First. 1-29.

Westergaard, Marit, Terje Lohndal \& Artemis Alexiadou. 2019. The asymmetric nature of V2: Evidence from learner languages. In Christensen, Ken Ramshøj, Henrik Jørgensen \& Johanna L. Wood (eds.), The Sign of the V: Papers in Honour of Sten Vikner, 709-733. Aarhus University. 
Westergaard, Marit, Natalia Mitrofanova, Roksolana Mykhaylyk \& Yulia Rodina. 2017. Crosslinguistic influence in the acquisition of a third language: The Linguistic Proximity Model. International Journal of Bilingualism 21(6). 666-682. doi:10.1177/1367006916648859

White, Lydia. 1990/1991. The verb-movement parameter in second language acquisition. Language Acquisition 1(4). 337-360.

White, Lydia. 2003. Second language acquisition and universal grammar. Cambridge University Press.

Williams, Sarah \& Björn Hammarberg. 1998. Language switches in L3 production: Implications for a polyglot speaking model. Applied Linguistics 19(3). 259-333.

Yang, Charles. 2002. Knowledge and learning in natural language. Oxford University Press.

Åfarli, Tor Anders \& Kristin Melum Eide. 2003. Norsk generativ syntaks. Novus.

CONTACT INFORMATION

Kjersti Faldet Listhaug

NTNU, Trondheim

kjersti.listhaug@ntnu.no

Guro Busterud

UiO, Oslo

guro.busterud@iln.uio.no

Anne Dahl

NTNU, Trondheim

anne.j.dahl@ntnu.no 